\title{
ESCLEROMORFISMO FOLIAR DE Aldina heterophylla SPRUCE EX BENTH (LEGUMINOSAE: PAPILIONOIDEAE) EM TRÊS CAMPINAS DA AMAZÔNIA CENTRAL ${ }^{1}$
}

\author{
Maria Gracimar Pacheco de ARAÚJO ${ }^{2}$ Maria Sílvia de MENDONÇA ${ }^{3}$
}

\begin{abstract}
RESUMO - Aldina heterophylla, Leguminosae: Papilionoideae, é uma espécie facilmente encontrada em diferentes campinas da Amazônia Central. Possui características morfológicas que revelam a sua interaçâo com o ambiente, apresentando variação no seu porte nas diversas campinas sob distintas condições de solo, luz e temperatura. O presente estudo foi realizado com a intenção de conhecer o grau de escleromorfismo das folhas em condições ambientais diferentes. De folhas ao sol e à sombra coletadas em trés campinas da Amazônia Central (campina aberta, campina alta e campina sombreada), foram feitos cortes histológicos e dissociação de epidermes, para a descrição anatômica das mesmas. De maneira geral, em todos os macroambientes a planta desenvolve estruturas escleromorfas. Sugere-se que Aldina heterophylla está melhor adaptada às condições ambientais da campina alta, visto que ali apresenta crescimento exuberante, em relação à campina aberta e à campina sombreada.
\end{abstract}

Palayras-chave: anatomia foliar, campinarana, macucu.

Leaf Scleromorphism of Aldina heteroplyylla Spruce ex Benth (Leguminosae: Papilionoideae) in Three "campinas" of Central Amazonia.

ABSTRACT - Aldina heterophylla (Leguminosae: Papilionoideae) is a species commonly found in campinas (dwarf forest on white sand) in central Amazonia. Some of its morphological characters vary according to the enviroment. It varies in size in the various campinas under different conditions of soil, light and temperature. The present study was made with the intention of understanding the amount of scleromorphism in different environmental conditions. Leaves collected under sun and shade conditions in three central Amazonia campinas ("open", "high" and "shaded" campina), were used for histological sections and epidermal preparations for anatomical description. In general, the plants showed scleromorphism in all the environments. It is suggested that Aldinat heterophylla is better adapted to the environmental conditions of "high" campina, where it showed more exuberent growth, than in "open" or "shaded" campina.

Key words: leaf anatomy, "campinarana", "macucu".

\section{INTRODUÇÃO}

Aldina heterophylla, vulgarmente conhecida como macucu, é uma árvore freqüente nas campinas da Amazônia Central. Possui folhas compostas; inflorescências abundantes, terminais ou axilares, paniculadas; flores hermafroditas; cálice gamossépalo; corola dialipétala, com pétalas brancas, estames numerosos, estigma simples e ovário súpero (Maguire et al., 1953). O fruto é macio, globoso e simples-sementado (Gentry, 1993). Apresenta muitas variações morfológicas nas folhas e nas flores, variando o número de foliolos, estames, pétalas e sépalas.

Na região de Manaus, esta espécie é facilmente encontrada na campina aberta (campina propriamente dita) e campina sombreada (campinarana) da Reserva

1 Parte de Dissertação (INPA/UA) da primeira autora.

2 Universidade do Amazonas, ICB/DB, Rua 103, 07, N/12, Cidade Nova II, 69.096-340, Manaus, AM. Fone: 645-1840.

3 Universidade do Amazonas, FCA/DCFDA, Rua Caracas, 06, Q/53, Campos Elíseos, 69.045300, Manaus, AM. Fone: 238-5842 
Biológica de Campina do INPA e na campina alta (campinarana) da Reserva Florestal Adolfo Ducke (Braga, 1982), apresentando variações no seu porte, de acordo com as condições do ambiente.

Na campina aberta, cresce sobre solo pobre, de areia lavada, sob luz intensa e temperatura elevada. Alcança 7-9 metros de altura aproximadamente, formando 0 estrato superior desse ambiente; ramifica próximo à base do caule e seus ramos estendem-se horizontalmente no chão, ocupando extensas áreas, de tal modo que apenas uma árvore é capaz de formar uma "ilha" de vegetação, contrastando com o solo nu de areia branca.

Na campina sombreada, desenvolve-se sobre solo arenoso recoberto por uma espessa camada de matéria orgânica, sob condições mais amenas de luz e temperatura. Aqui a espécie apresenta um porte mais elevado que na campina aberta, em torno de 9 a 12 metros de altura, com o tronco e as ramificações mais grossos e a copa da árvore também formando o dossel.

Na campina alta, encontra-se sobre uma superficie de solo arenoso seguido por solo argilo-arenoso, vivendo sob condições climáticas similares à floresta de mata densa, apesar de encontrar-se em floresta de mata rala. Neste ambiente, a espécie possui porte em torno de 22 a 30 metros de altura, o caule podendo alcançar mais de um metro de diâmetro e alguns individuos apresentam raizes tabulares. A copa atinge o dossel, apresenta-se rala, com as primeiras ramificações bastante grossas e tortuosas, distando cerca de 17 metros do chão, dependendo da altura da árvore.

De forma geral, nos três ambientes, a planta desenvolve um caule grosso e tortuoso, com ramificações horizontais ou quase horizontais, casca espessa e rugosa, com grande capacidade de retenção de água e matéria orgânica. Estas características conferem à espécie um importante papel ecológico. Tanto a arquitetura dos ramos como as propriedades da casca favorecem a instalação de liquens, musgos e hepáticas, dando-lhe um aspecto conspícuo dentro do ecossistema, acentuado ainda mais pela enorme quantidade de epifitas que abriga em seus ramos, principalmente espécies de Orchidaceae e Bromeliaceae.

No presente estudo fez-se a descrição anatômica do foliolo de folhas de Aldina heterophylla coletado de ramos de sol e de sombra de plantas presentes nas três campinas citadas, a fim de conhecer o grau de escleromorfismo foliar da espécie, em condições ambientais diferentes.

\section{MATERIAL E MÉTODOS}

O material botânico foi coletado na floresta de campinarana da Reserva Biológica Adolfo Ducke, localizada na AM-10, MAO-Itacoatiara, $\mathrm{km}$ 27, e nas florestas de campina e campinarana da Reserva Biológica da Campina do INPA, localizada na BR-174, MAOCCI, km 60 (Fig. 1).

Em cada campina foram escolhidas quatro árvores ao acaso, retirados galhos de sol e de sombra e coletados os folíolos apicais das folhas tri- folioladas. Destes foram tiradas secções, do ápice, do meio e da base da lâmina foliolar (limbo) para dissociação das epidermes e secções das regiões mediana do limbo, pulvinulo, peciolo e púlvino, para cortes histológicos transversais (Fig. 2 e Tab. 1). 


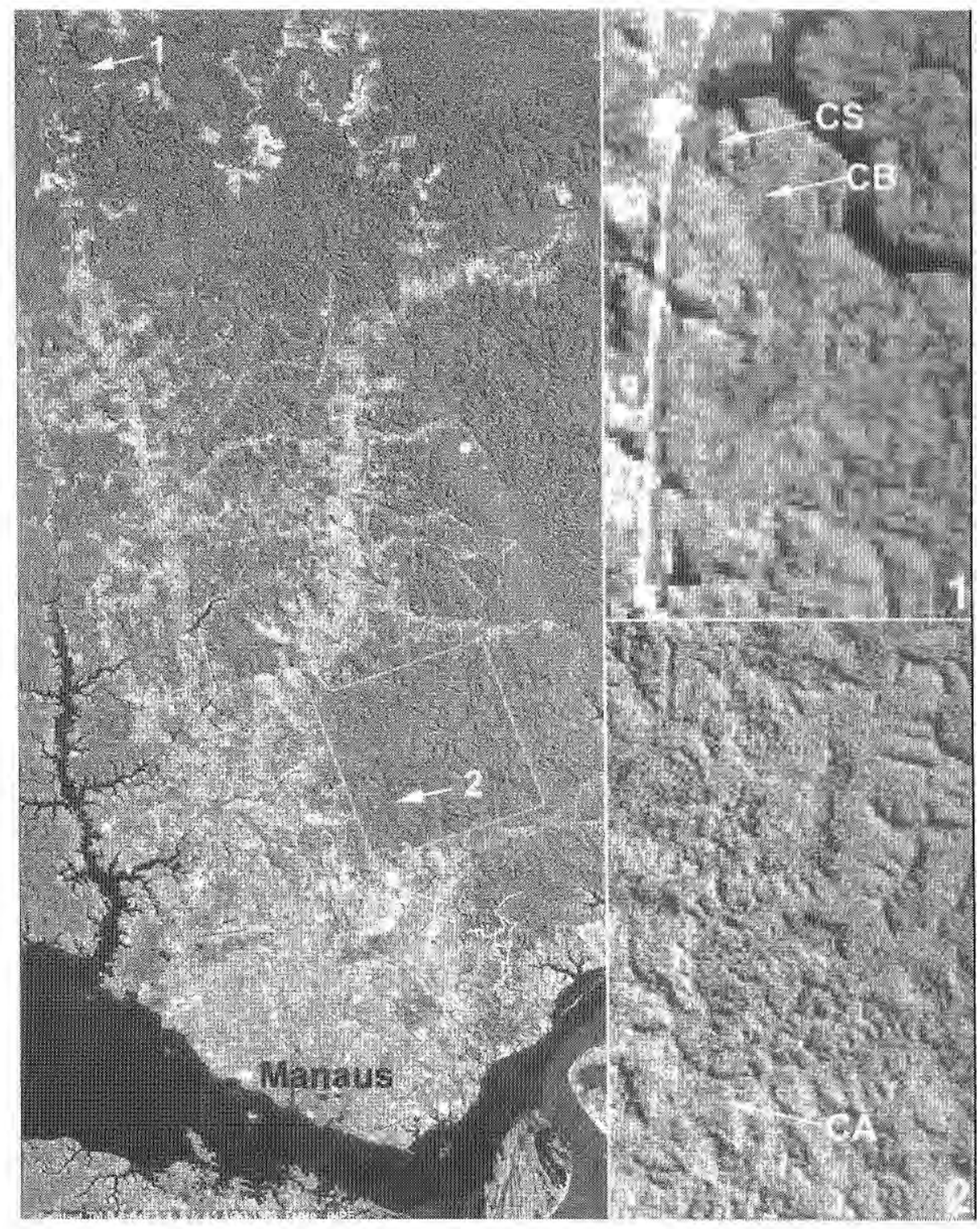

Figura 1. Locais de coleta. Foto maior, acima à esquerda: Reserva Biológica da Campina do INPA (1); abaixo. Reserva Florestal Adolfo Ducke, destacado a Campinarana (2). Fotos menores, 1: Detalhe da Reserva da Campina do INPA, destacando a Campina Sombreada (CS) e a Campina Aberta (CB); 2: Detalhe da Reserva Ducke, destacando a Campina Alta (CA). 


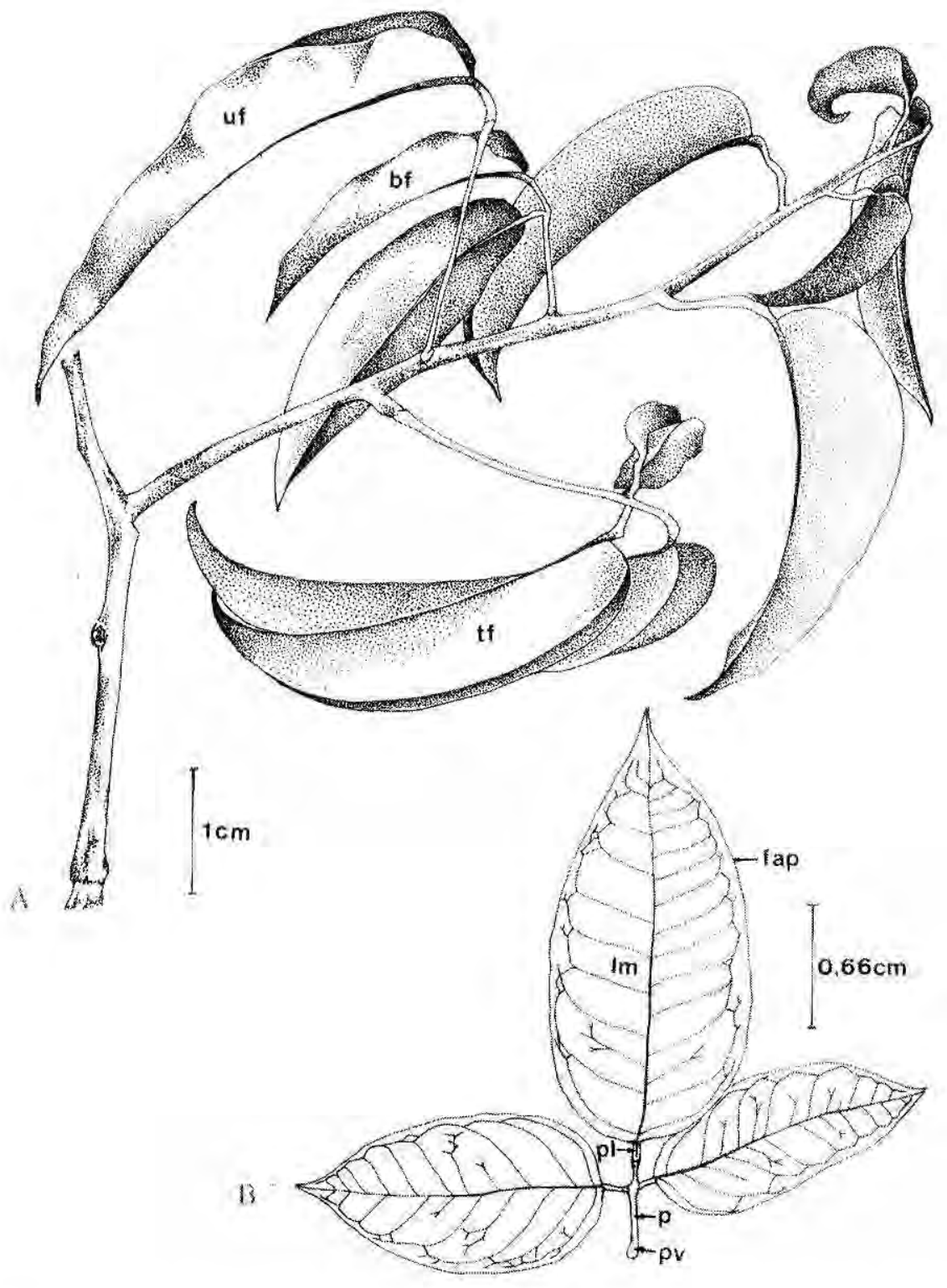

Figura 2. Aspecto geral do ramo (A) e folha tri-foliolada (B) de Aldina heterophylla Spruce ex Benth. uf, folha unifoliolada; bf, folha bifoliolada; tf, folha trifoliolada; fap, foliolo apical; $\mathbf{l m}$, lâmina do foliolo; $\mathbf{p l}$, pulvínulo; $\mathbf{p}$ peciolo; $\mathbf{p v}$, púlvino. 
Tabela 1. Amostragem utilizada para coleta do material botânico e análise das estruturas, usando-se quatro árvores de cada local de coleta.

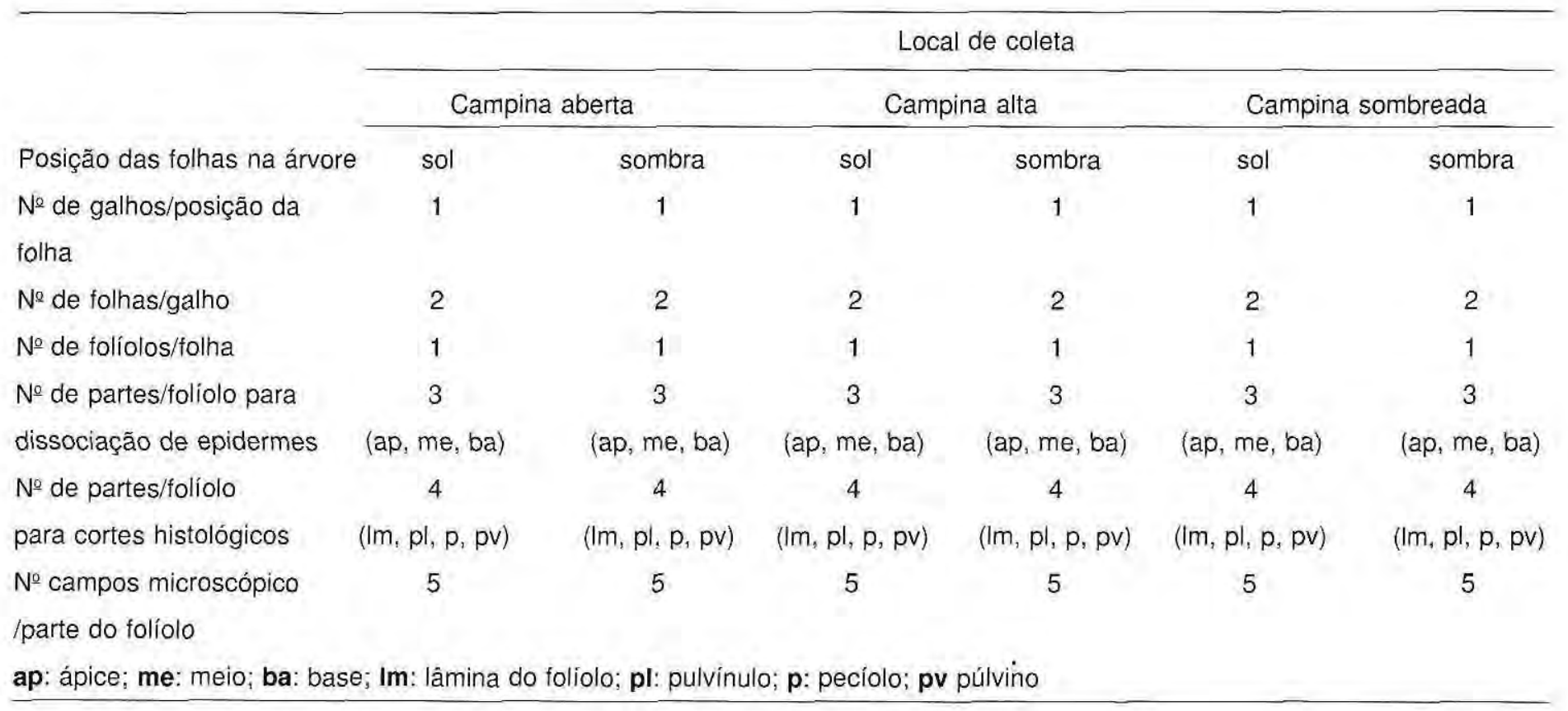


As epidermes foram dissociadas $\mathrm{em}$ água sanitária em diversas concentrações (70-100\%), fixadas em álcool a 50\% glicerinado, coradas com Astrablau e montadas em glicerina (Medri, 1977; Mendonça, 1980).

Os cortes histológicos foram feitos com material fixado em álcool a $70 \%$ glicerinado, desidratado em série alcoólica crescente, emblocados em parafina, cortados em micrótomo rotativo a 10 $12 \mathrm{~mm}$, corados em Astrablau-Fucsina básica e montados em Bálsamo do Canadá . Usando-se material fresco, foram feitos ainda cortes para efetuar-se os microtestes de grãos de amido, taninos, cutina e lignina (Patiño, 1986).

Também foram feitos cortes à mão livre de material fixado em FAA, montados sem qualquer corante, para obtenção de fotomicrografias. Estas foram feitas em fotomicroscópio óptico Axioskop com câmara MC 80 .

Foi feita ainda, microscopia eletrônica de varredura (Scanning Electron Microscope-SEM) da superficie do limbo, pulvínulo e pecíolo.

Efetuou-se medições e contagens das células epidérmicas, parenquimáticas e xilémáticas do limbo, pulvínulo, peciolo e púlvino, para complementar a descrição anatômica do foliolo. Todas as medições foram feitas em microscópio monocular com ocular micrometrada e as contagens em microscópio binocular com ocular de 10x e objetiva de 50x.

\section{RESULTADOS}

\section{3,1. Lâmina foliolar (limbo)}

Epiderme: a epiderme da lâmina foliolar é glabra e hipoestomática. A cutícula é espessa, recobrindo as paredes celulares periclinais externas e penetrando nas paredes anticlinais.

Em vista frontal, a face adaxial apresenta células de forma geralmente retangular, medindo cerca de $12 \mathrm{~mm} x$ $16 \mathrm{~mm}$, com paredes espessas, que podem ser retas (na maioria das folhas de sol) ou sinuosas (na maioria das folhas de sombra). Em secção transversal as células são cúbicas ou retangulares com cerca de $16 \mathrm{~mm}$ de altura. Em microscopia eletrônica de varredura (SEM), observa-se que nas folhas da campina alta, o depósito de ceras epicuticulares é amorfo, enquanto que nas folhas das campinas aberta e sombreada, este forma ornamentações onduladas (Fig. 3).

A face abaxial, em vista frontal, apresenta células de forma e tamanho semelhantes às da epiderme adaxial. Em secçâo transversal, possuem forma tabular com cerca de $14 \mathrm{~mm}$, mas também podem apresentar forma cúbica. Os estômatos são do tipo paracítico, possuem forma principalmente elítica, ocorrendo também formas arredondadas ou alongadas; estão dispostos em aglomerações nas regiões intercostais, mas ausentes ao nivel das nervuras. Nestas, raras vezes, observam-se estruturas semelhantes a estômatos. Em SEM, observam-se estômatos protegidos por ceras epicuticulares, localizadas acima da epiderme, impossibilitando a visualização do ostiolo (Fig. 4).

Mesofilo: o mesofilo possui organização dorsiventral. $\mathrm{O}$ parênquima paliçádico é constituído em dois estratos. As células possuem formas alongadas e cilindricas, medindo cerca de $41 \mathrm{~mm}$ de comprimento e $10 \mathrm{~mm}$ espessura. $\mathrm{O}$ 

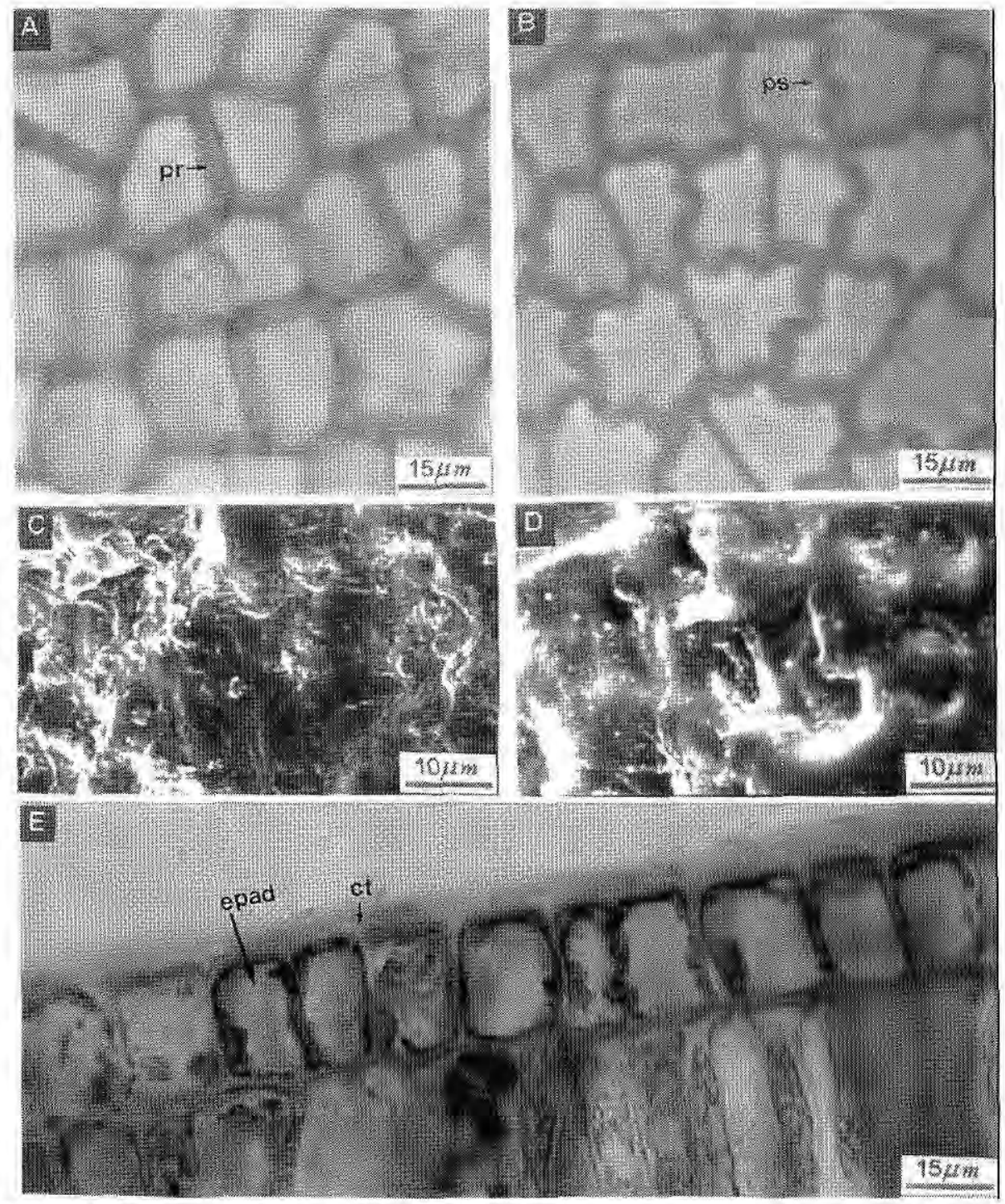

Figura 3. Epiderme da face adaxial do foliolo. A, vista frontal de un foliolo de sol. B, vista frontal de um foliolo de sombra. C, superfície de um foliolo da campina alta em SEM. D, superficie de um folíolo da campina sombreada em SEM. E, detalhe em corte transversal. pr, parede etas; ps, parede sinuosa; epad, epiderme adaxial; ct, cutícula. 

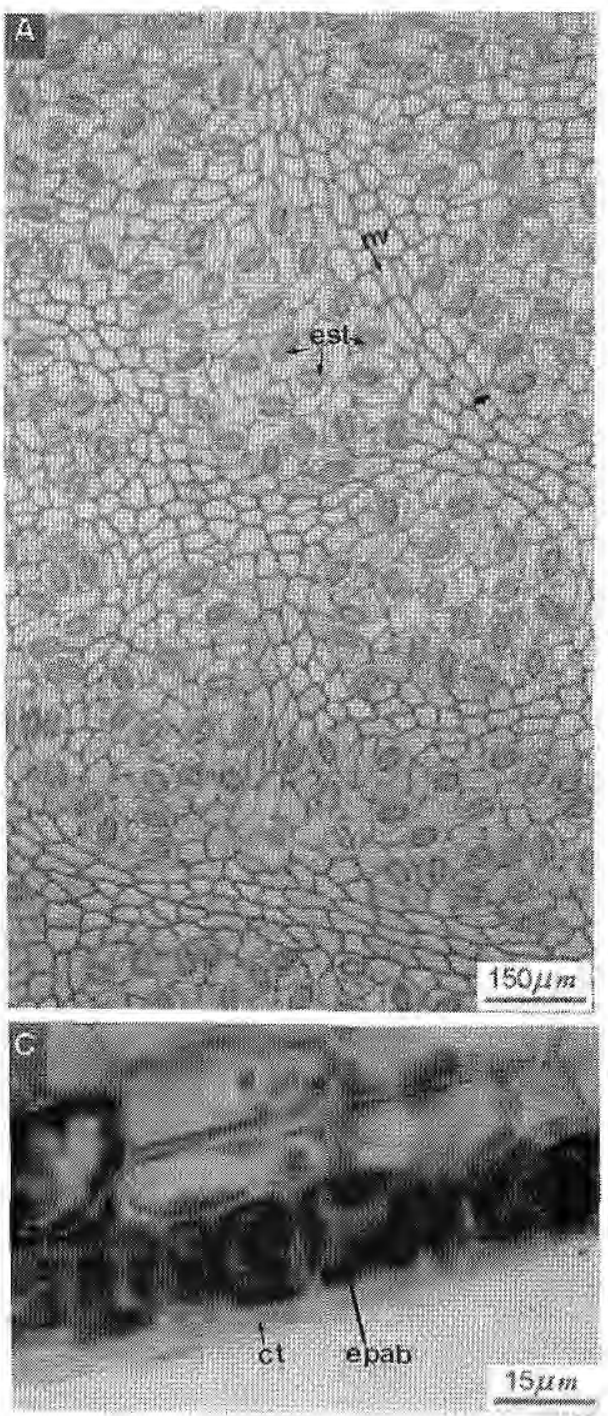

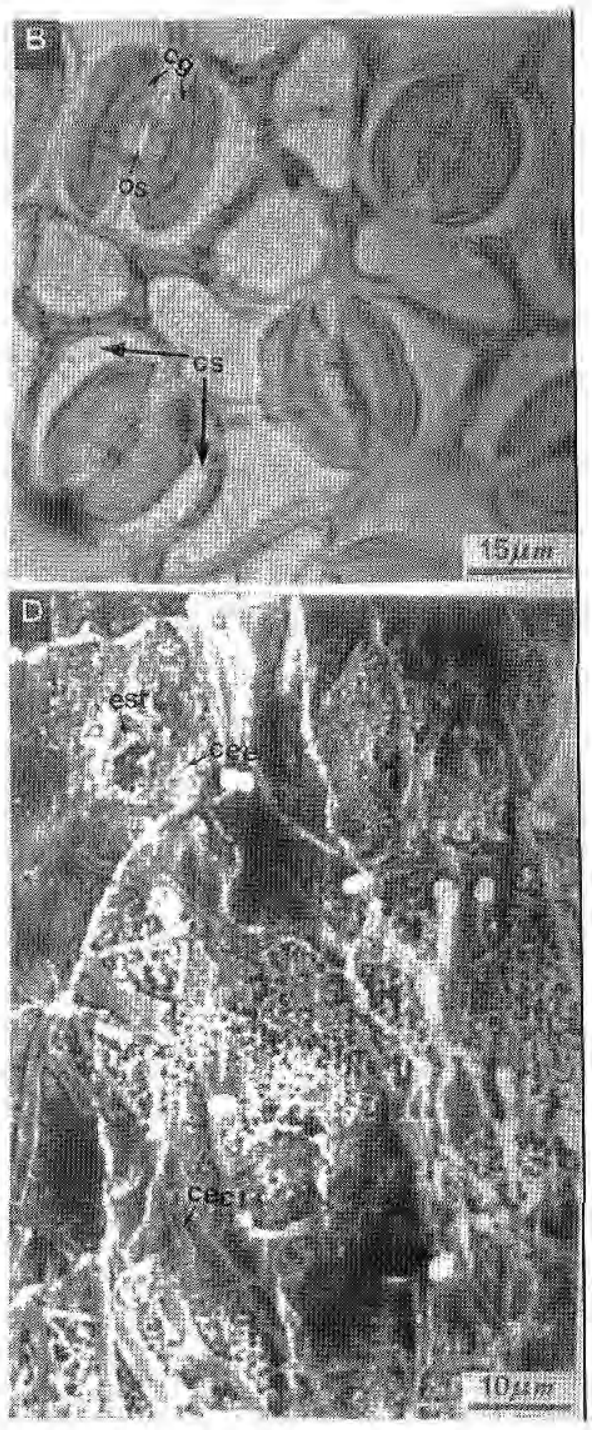

Figura 4. Epiderme da face abaxial do foliolo. A, aspecto geral em vista frontal. B, detalhe em vista frontal. C, detalhe em corte transversal. D, aspecto da superficie em SEM. est, estômato; cg, célula-guarda; os, ostiolo; cs, célula subsidiária; nv, nervura; ct, cuticula; epab, epiderme abaxial; cee, cera epicuticular sobre estômato; cec, cera epicuticular sobre células epidérmicas. 
parênquima lacunoso apresenta, logo após a epiderme abaxial, um ou dois estratos de células retangulares, perpendiculares às células epidérmicas, sendo frequentemente interrompido pelas câmaras subestomáticas; a camada mais interna do mesofilo apresenta células alongadas, frequentemente contendo gràos de amido e conectadas umas com as outras através de curtas ramificações laterais, formando um tecido frouxo, cheio de espaços intercelulares. Imerso no parênquima clorofiliano, observam-se os feixes vasculares, colaterais, cercados por um espesso anel de fibras, e mais externamente, uma extensão de bainha do feixe, formado por um tecido fundamental denso, constituido de várias camadas de células sem cloroplastos, estendendo-se até as epidermes adaxial e abaxial (Fig. 5).

Nervura central: em secção transversal observa-se que as faces adaxial e abaxial da nervura central são recobertas por uma cutícula espessa e invaginante que, em SEM, revelam as ceras epicuticulares depositadas em estrias. As células da epiderme adaxial apresentam-se alongadas, semelhantes às paliçadas, com cerca de $24 \mathrm{~mm}$ de altura. A epiderme abaxial possui a maioria das células de forma cúbica, com $14 \mathrm{~mm}$ de altura, aproximadamente. $O$ parênquima subepidérmico apresenta espessamento uniforme das paredes celulares. O sistema vascular é formado por vários feixes colaterais, dispostos lado a lado formando um arco, circundado pelo esclerênquima. Os vasos do xilema medem cerca de $14 \mathrm{~mm}$ a $22 \mathrm{~mm}$ de diâmetro. $\mathrm{O}$ parênquima central é formado por células grandes e ricas em taninos (Fig. 6).

\section{2. Pulvínulo}

Em corte transversal, a superficie epidérmica apresenta-se sinuosa, recoberta por uma espessa cutícula, com ceras formando ornamentações bastante elevadas. As células epidérmicas são tabulares, com cerca de $16 \mathrm{~mm}$ de altura. Logo abaixo da epiderme, localiza-se um parênquima subepidérmico com poucas camadas de células, de dificil visualização. O córtex é quase que totalmente obscurecido por uma densa concentração de células taniferas. $\mathrm{Na}$ região média do parênquima cortical destacam-se grandes células pétreas, isoladas ou em pequenas aglomerações. O tecido vascular, na região mediana, é formado por vários feixes dispostos de maneira serpentiforme, com floema externo ao xilema radial, bem desenvolvido e, outros feixes de sutura, menores. $\mathrm{O}$ esclerênquima encontra-se associado aos feixes de forma descontinua (Fig. 7).

\subsection{Pecíolo}

Possui cuticula espessa, recobrindo as paredes periclinais externas das células epidérmicas e penetrando por entre as paredes anticlinais das mesmas; em SEM observam-se ceras epicuticulares depositadas em placas. As células epidérmicas são geralmente cúbicas, medindo em torno de $13 \mathrm{~mm}$ de altura. Logo abaixo da epiderme localiza-se um parênquima colenquimatoso, seguido de numerosas células pétreas de pontuações visiveis, dispersas no córtex. O sistema vascular, na região mediana, é formado por um feixe principal, concêntrico, com floema 

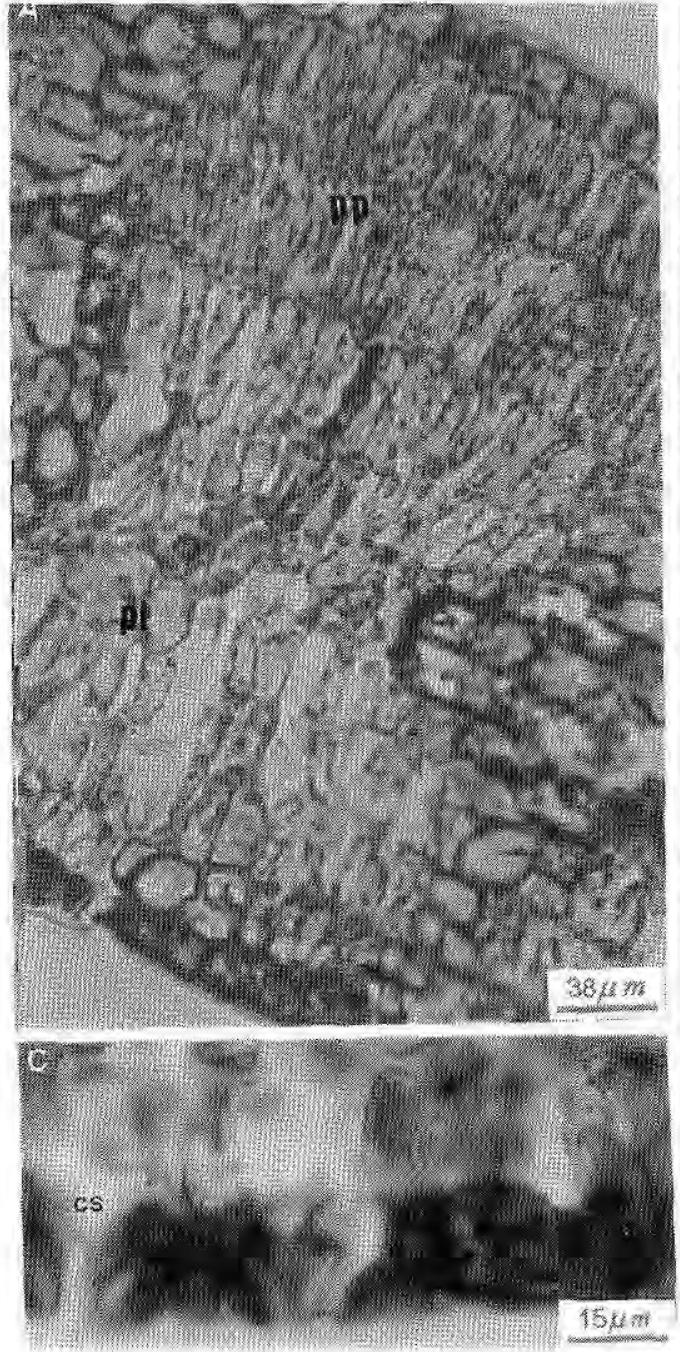
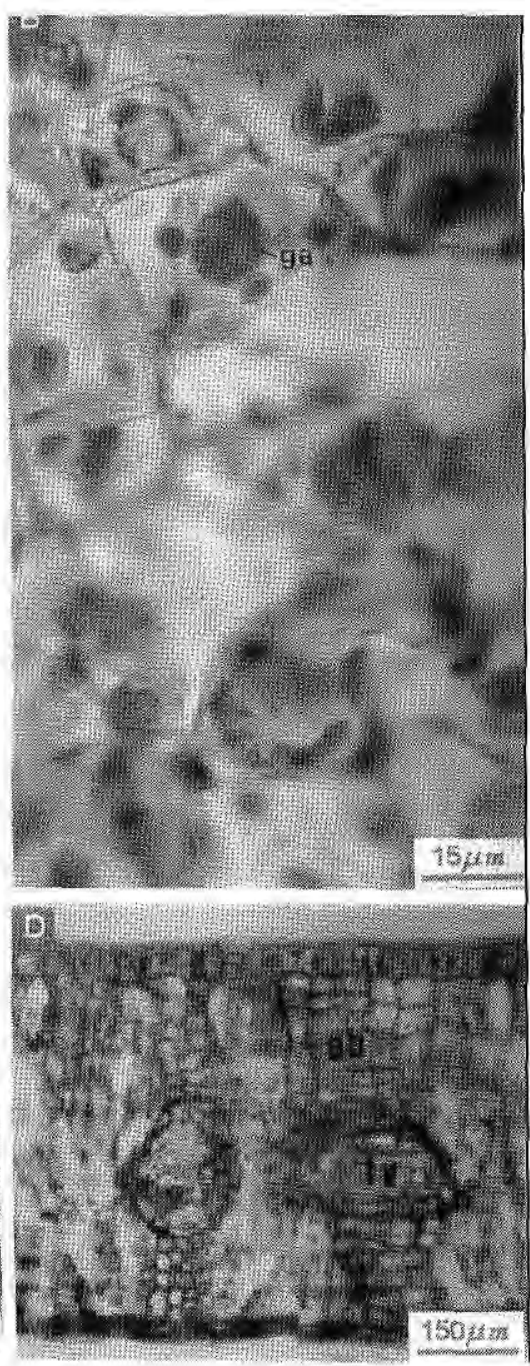

Figura 5. Detalhe da lãmina foliolar em corte transversal; A, mesofilo destacando os parênquimas paliçádico (pp) e lacunoso (pl). B. parênquima lacunoso destacando-se gràos de amido (ga). $\mathrm{C}$, parênquima lacunoso acima da epiderme abaxial, destacando-se câmara subestomáticas (cs). D, feixes vasculares (fv) e extensão da bainha do feixe (eb). 

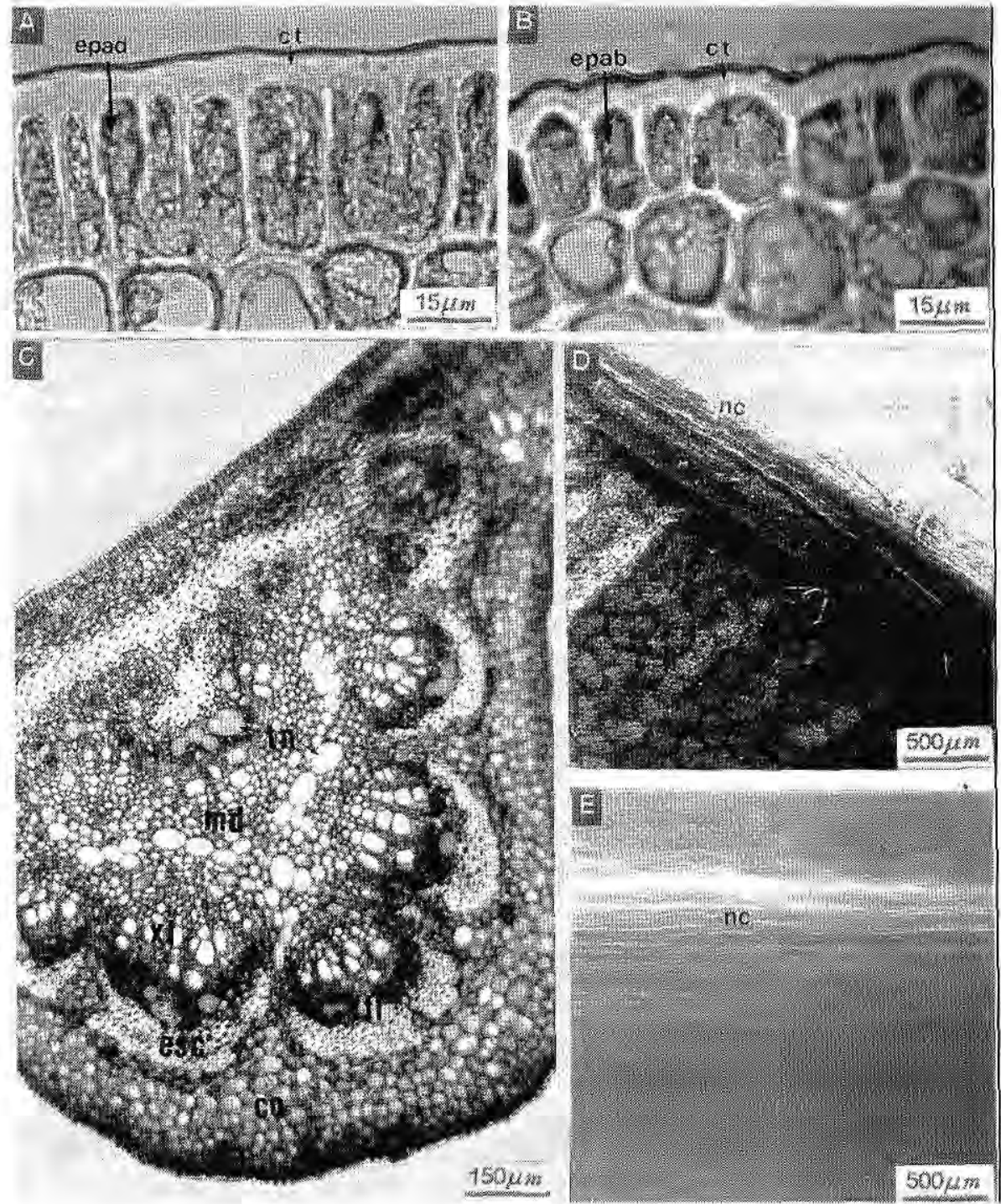

Figura 6. A-C, detalhes da nervura central em corte transversal; D, SEM da superficie adaxial e E, SEM da superficie abaxial. apad, epiderme adaxial, epab, epiderme abaxial ct, cutícula, tn, células taniferas; fl, floema; xl, xilema; md, medula; esc, esclerênquima; co, corttex; cn, nervura central. 

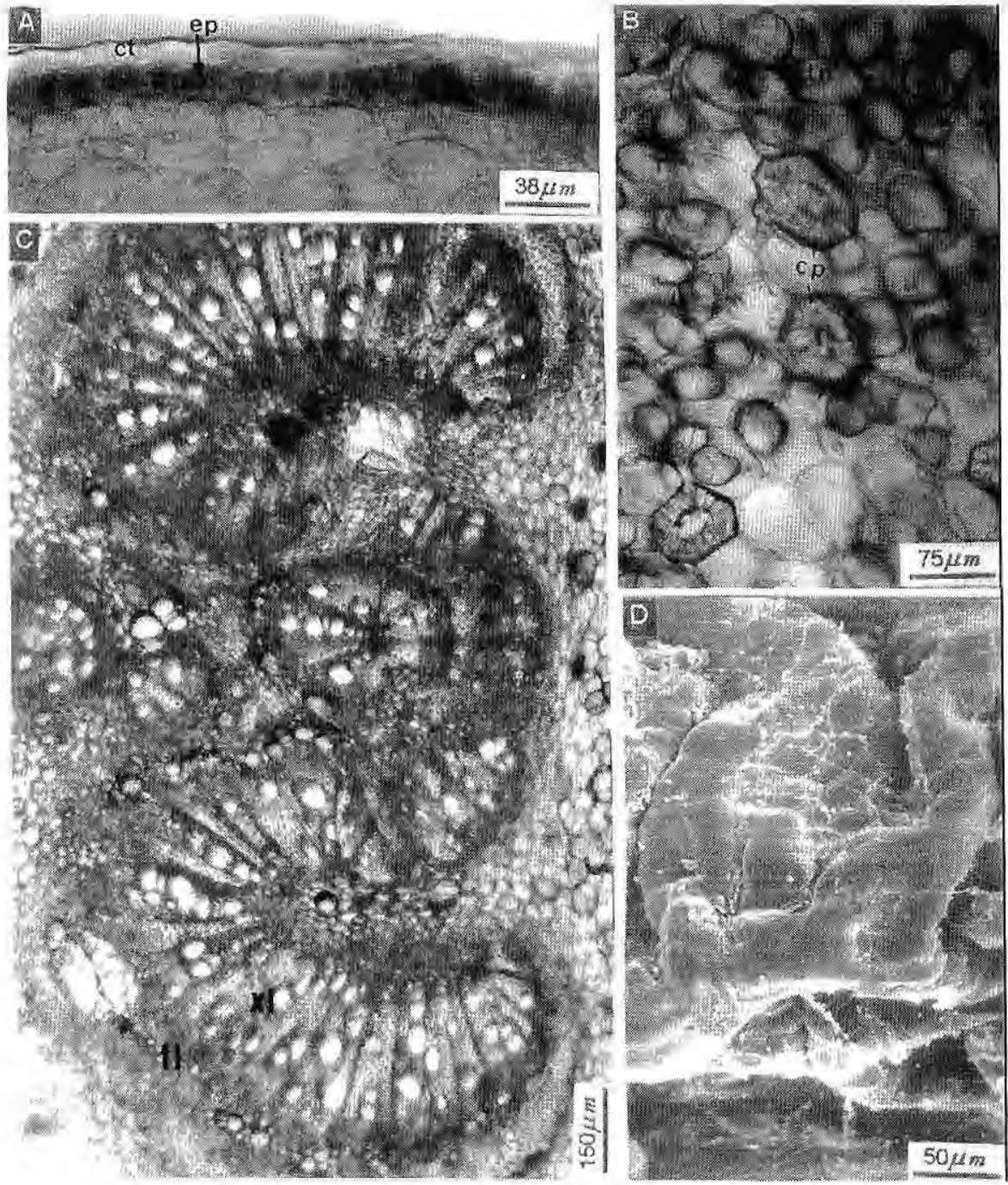

Figura 7. Detalhes do pulvinulo em corte transversal: A, epiderme; B, regiào cortical; C, sestema vascular e D, superficic do órgão $\mathrm{cm}$ SEM. ct, cuticula; ep, epiderme; tn, células taniferas; $\mathbf{c p}$, célula pétrea; $\mathbf{f l}$, floema; $\mathbf{x I}$, xilema. 
externo ao xilema e ambos circundados por um anel espesso e contínuo de esclerênquima; no córtex situa-se um feixe secundário colateral, em arco aberto. Nos pólos do floema observam-se células taniferas, grandes, reunidas em grupos de 3 a 4. O xilema apresenta disposição radial, com vasos medindo cerca de $10 \mathrm{~mm}$ a $32 \mathrm{~mm}$ de diâmetro; o parênquima radial é formado por células pequenas, com paredes lignificadas. A medula apresenta células de parênquima lignificado, algumas contendo tanino (Fig. 8).

\subsection{Púlvino}

Apresenta estrato cuticular espesso e sinuoso, cobrindo a epiderme formada de células tabulares medindo cerca de $16 \mathrm{~mm}$ de altura e anexo a estas, frequentemente encontram-se células taniferas. $\mathrm{O}$ parênquima subepidérmico é formado por células globosas de paredes delgadas; na região média do córtex concentram-se várias células taniferas, que rareiam à medida que surgem enormes células pétreas, medindo cerca de $64 \mathrm{~mm}$ no eixo maior, com pontuações visíveis e lúmem aberto. $\mathrm{O}$ sistema vascular é formado por um feixe reniforme, colateral, com floema externo ao xilema. Externamente, o esclerênquima que circunda o feixe é menos desenvolvido que na nervura central e peciolo. Os vasos xilemáticos estão dispostos radialmente; os maiores medindo aproximadamente $42 \mathrm{~mm}$ de diâmetro e os menores $17 \mathrm{~mm}$. A medula é formada por parênquima de paredes espessadas, com as células maiores medindo em torno de $41 \mathrm{~mm}$ e as menores em torno de $16 \mathrm{~mm}$; além destas, encontram-se várias células taniferas (Fig. 9).

\section{DISCUSSÃO}

Cuticula espessa, células epidérmicas com paredes espessas, estômatos em alta densidade e protegidos por ceras, parênquima paliçádico e esclerênquima bem desenvolvidos, são caracteristicas encontradas em Aldina heterophylla, que poderiam ser entendidas do ponto de vista ecológico, como uma adaptação às condições xéricas. Entretanto, nas campinas amazônicas a água não è o único fator limitante do crescimento vegetal, devendo-se levar em consideração outros fatores ambientais que influenciam a estrutura foliar, quais sejam, luz, temperatura, tipo de solo e nutrientes.

Tais fatores, em conjunto ou isoladamente, certamente estão contribuindo para o xeromorfismo das folhas de Aldina heterophylla, a exemplo do que já foi visto em estudos anteriores anátomo-ecológicos e anátomo-fisiológicos (Ferri, 1960; Lleras, 1977; Leite \& Lleras, 1978; Lleras \& Medri, 1978; Medri \& Lleras, 1979, 1981).

Fahn (1985), lembra que o termo xeromorfismo não é exclusivo das xerófitas e que nem todas as xerófitas exibem necessariamente caracteristicas xeromórficas. Nesta discussão prefere-se usar o termo escleromorfismo, sendo usado o termo xeromorfismo apenas em relação ao ambiente mais seco.

Aldina heterophylla apresenta cuticula foliar bastante espessa; porém, o espessamento da cutícula, isoladamente, não pode ser considerado um caráter escleromórfico, pois sua relação com o 

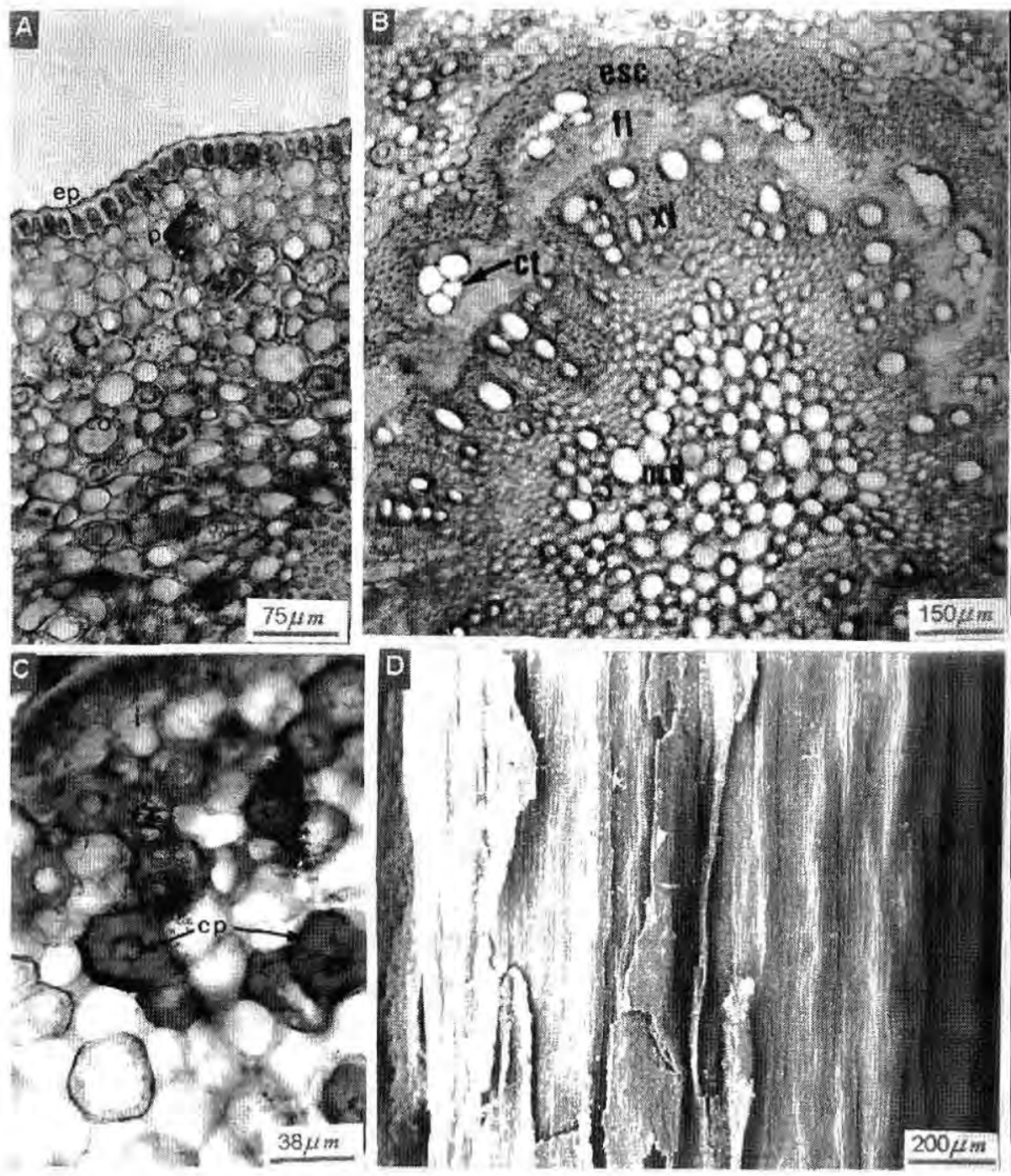

Figura 8. Detalhes do peciolo em corte transversal: A, epiderme e córtex; B, sistema vascular; C, córtex e D, SEM da superfície do órgão. ep, epiderme, pc, parênquima colenquimatoso; $\mathbf{c p}$, córtex; esc, esclerênquima; fl, floema; $\mathbf{x l}$, xilema; md, medula $\mathbf{c p}$, célula pétrea pétrea; $\mathbf{c t}$, células taniferas. 


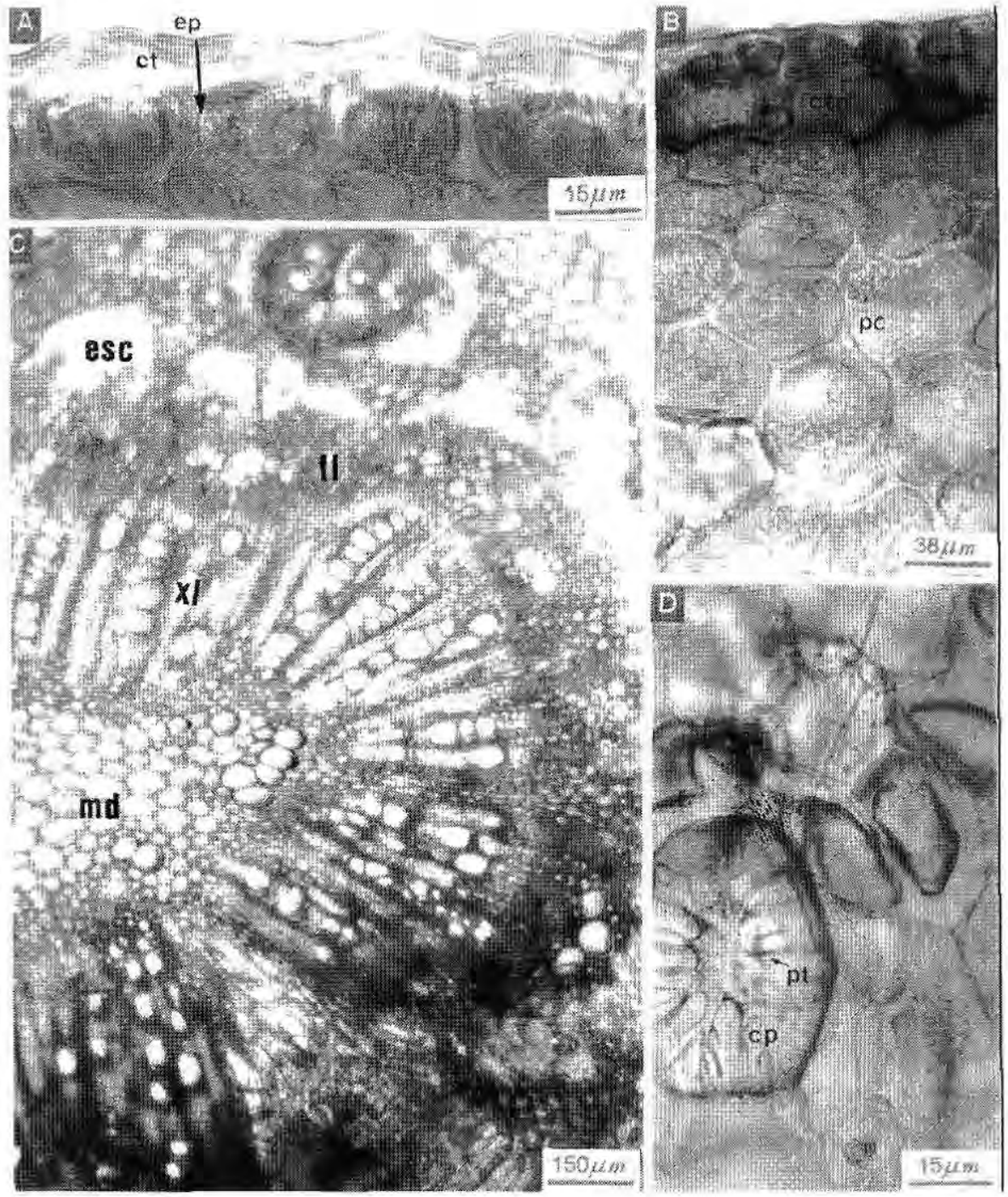

Figura 9. Detalhes do púlvino em corte transversal: $A$, epiderme; $B$, córtex subepidérmico; $C$, tecido vascular e D, um detalhe do córtex. ep, epiderme; ct, cutícula; $\mathbf{c t n}$; células taníferas; $\mathbf{p c}$, parênquima cortical; esc, esclerênquima; fl, floema; $\mathbf{x l}$, xilema; md, medula; $\mathbf{c p}$, célula pétrea; $\mathbf{p t}$, pontuação. 
ambiente ainda é pouco conhecida. A cutícula varia sensivelmente em plantas distintas e as condições ambientais e outros fatores desconhecidos influem sobre o seu desenvolvimento (Esau, 1985). De acordo com Cutter (1986), vários fatores podem afetar a formação de ceras, mas estas são mais desenvolvidas quando encontram-se sob alta intensidade luminosa. Nas folhas da campina alta, onde as condições de luz são mais amenas, nota-se menor deposição de cera sobre os estômatos, em relação às folhas da campina aberta e da campina sombreada.

Quanto ao espessamento das paredes das células epidérmicas, Arens (1958) justifica que a elevada taxa fotossíntética causa um "superávit" de hidratos de carbono e derivados, eliminados sob forma de membranas espessas. No estudo com Hevea brasiliensis, Medri \& Lleras (1980) concluem que o espessamento das paredes das células epidérmicas é uma adaptação à perda excessiva de água nos estratos mais xerofiticos da árvore. Em Aldina heterophylla pode-se relacionar esse espessamento à alta intensidade luminosa possivelmente aumentando a atividade fotossintética.

$O$ fato de Aldina heterophylla possuir estômatos somente na face abaxial pode ser interpretado como uma adaptação ecológica que permite à planta controlar mais eficientemente a transpiração, mas é provável que esta seja também uma herança genética. Segundo Metcalfe \& Chalk (1950), estômatos do tipo paracitico são os mais comumente encontrados nas subfamilias Caesalpinoideae e Papilio- noideae, apesar de ambas possuirem grande diversidade na disposição das células subsidiárias. A respeito das estruturas semelhantes aos estômatos sobre as nervuras, possivelmente, referem-se aos hidatódios citados por Esau (1985).

De acordo com Fahn (1985) e Esau (1985), o parênquima lacunoso apresenta uma organização mais variada que o paliçádico e, se este último é pluriestratificado a camada mais externa apresenta forma e disposição cada vez mais parecidas com o lacunoso, como observado em Aldina heterophylla.

A presença de esclerênquima em torno dos feixes vasculares do mesofilo de Aldina heterophylla pode está relacionada com a sindrome de escleromorfismo em decorrência do ambiente, ou está diretamente ligada à herança genética. Metcalfe \& Chalk (1950) citam que feixes vasculares imersos no mesofilo acompanhados de esclerênquima, é uma característica muito comum em vários gêneros de Caesalpinoideae e podem estar presentes ou não nas Papilionoideae.

As células epidérmicas semelhantes à paliçada observadas na epiderme adaxial da nervura central, são mencionadas por Metcalfe \& Chalk (1950) para toda a lâmina foliar do gênero Sclerolobium (Caesalpinoideae). Vale comentar que os autores descrevem as células epidérmicas em geral, como sendo papilosas ou subpapilosas, tanto em Caesalpinoideae como em Papilionoideae. Na nervura central de Aldina heterophylla, pode-se dizer que há uma tendência à papilosidade nas células epidérmicas.

Por ser restrito às folhas recom- 
postas, o pulvinulo não é encontrado comumente, por isso pouco se sabe sobre a sua estrutura anatômica. Por ter função de articulação, esperava-se encontrar um volume menor de tecido xilemático em relação ao parenquimático. A presença de células pétreas e esclerênquima perivascular no órgão provavelmente tem relação com a síndrome de escleromorfismo da planta.

O que desperta atenção no pecíolo é o espesso anel de esclerênquima formado por fibras perivasculares semelhantes às fibras gelatinosas analisadas por Paviani (1974), quando estudou Plathymenia reticulata e que estão associadas ao lenho de tensão que se forma na parte adaxial dos caules inclinados e ramos das Angiospermas. Porém, julga-se possível a presença do lenho de tensão em órgãos foliares, principalmente peciolos, uma vez que os mesmos também estão sujeitos a estímulos de curvatura, luminosidade e ações mecânicas. Células pétreas presentes no córtex, feixes adicionais em arco e sistema vascular fortemente protegido por esclerênquima, são características descrita por Metcalfe \& Chalk (1950) para vários gêneros de Caesalpiniaceae, que também referemse ao sistema vascular composto de feixes separados ou contínuo consistindo de um único feixe, como características de Papilionoideae.

De todas as partes da folha, o púlvino é a estrutura que apresenta células parenquimáticas com paredes mais delgadas; provavelmente esta característica está associada à sua função de articulação. Segundo Esau (1974), o processo de articulação das folhas através do púlvino pode ser estimulado pelas condições ambientais ou ser autônomo. Este processo pode estar associado a variações do turgor e a concomitantes alterações de tamanho e formato das células do parênquima fundamental. A exemplo do pulvinulo, células pétreas e tecido esclerenquimático presentes neste órgão também ressaltam o caráter escleromórfico da planta.

Metcalfe \& Chalk (1950) referem-se às células secretoras de taninos, frequentes no mesofilo das Papilionaceae e raros ou ausentes no mesofilo das Caesalpiniaceae. Em Aldina heterophylla também são raras no mesofilo; porém, são freqüentes na nervura central, peciolo e abundantes no córtex do pulvínulo e púlvino.

Nota-se que há uma tendência de escleromorfismo mais acentuado nas folhas da campina aberta, seguidas das folhas da campina sombreada e formando um extremo oposto com as folhas da campina alta. Entretanto, considerando que não há mudanças estruturais drásticas nas folhas das diferentes campinas e que, morfologicamente a planta expressa grande variação no seu porte, sugere-se que Aldina heterophylla está melhor adaptada às condições ambientais da campina alta, visto que, apresenta crescimento exuberante, em relação à campina aberta e à campina sombreada.

\section{CONCLUSÕES}

Aldina heterophylla não apresenta diferenças anatômicas aparentes em microscopia ótica, entre os foliolos das três campinas estudadas. Em microscopia eletrônica de varredura detectam-se discretas variações no padrão e 
quantidade de ceras epicuticulares.

De maneira geral, em todas as campinas as plantas desenvolvem estruturas escleromorfas.

Os resultados obtidos não podem ser conclusivos em relação ao grau de plasticidade fenotipica apresentado pela espécie ou mesmo à maior adaptabilidade da planta neste ou naquele ambiente. Fazse necessária uma análise mais detalhada da anatomia foliar, com estudos mais abrangentes incluindo parâmetros que não foram aqui considerados, tais como: espessura das paredes celulares, relações volume-superfície e parênquima paliçádico-lacunoso, densidade de venação do mesofilo e quantificação do xilema.

\section{Bibliografia citada}

Arens, K. 1958. O cerrado como vegetação oligotrófica. Bol, Fac. Filos., Ciênc. e Letras da Univ. São Paulo,(224) Sêr. Botânica, (15); 58-77.

Braga, P. I. S 1982. Aspectos Biológicos das Orchidaceae de uma Campina da Amazônia Central: II - Fitogeografía das Campinas da Amazỏnia Brasileira Tese. INPA/FUA. 345p.

Cutter, E. C. 1986. Anatomia vegetal: Parte I Células e Tecidos, Botucatu: Roca. 304p.

Esau, K. 1974. Anatomia das Plantas com Sementes. São Paulo: Edgard Blucher. 393pp.

Esau, K. 1985. Anatomia Vegetal. 3. ed. Barcelona: Omega. 779pp.

Fahn, A. 1985. Anatomia Vegetal. Madrid: Pirámide. 599pp.

Ferri, M. G. 1960, Contribution to the knowledge of the ecology of the "Rio Negro Caatinga" (Amazon), Bull. Res. Counc. of Israel, (8D): 195-208.

Gentry, A. H. 1993, Papilionoideae. In: Gentry, A. H. 1993. A field guide to the families and genera of woody plants of Northwest South America (Colombia, Ecuador; Peru) with suplementary notes on herbaceous taxa. Washington: Dept. of. Conservation Biology, Conservation International, p.531.

Leite, M. C.; Lleras, E. 1978. Ecofisiologia de plantas da Amazônia: 1 - Anatomia foliar e ecofisiologia de Pagonophora schomburgkiana Miers. (Euphorbiaceae). Acta Amazonica, 8(3): 365-370.

Lleras, E. 1977. Differences in stomatal number per unit area within the same species under different micro-environmental conditions: A working hypothesis. Acta Amazonica, 7(4):-473-476.

Lleras, E.; Medri, M. E. 1978. Comparação anatômica entre folhas diplóides e poliplóides do híbrido Hevea brasiliensis_ $\mathrm{x}$ benthamiana (IAN 717). Acta Amazonica, 8(4): 565-575.

Maguire, B.; Cowan, R. S.; Wurdack, J. J. 1953. The Botany of the Guayana Highland. A Report of the Kunhardt, the Phelps, and the New York Botanical Garden Venezuelan Expeditions. Memoir of N. Y. Botanical Garden, 8(2):109-110.

Medri, M. E. 1977. Alguns aspectos da anatomia ecologica de folhas de Hevea brasiliensis Muell. Arg. Dissertaçăo. INPA/FUA. 108pp.

Medri, M. E.; Lleras, E. (1979). Ecofisiologia de plantas da Amazônia. 2 - Anatomia foliar e ecofisiologia de Bertholetia excelsa Humb. \& Bonpl. (Castanha-do-Pará) - Lecythidaceae. Acta Amazonica, 9(1): 15-23.

Medri, M. E.; Lleras, E. 1980. Aspectos da anatomia ecológica de folhas de Hevea brasiliensis Muell. Arg. Acta amazonica. 10(3): 463-493.

Medri, M. E.; Lleras, E. 1981. Comparação anatômica entre folhas de um clone diplóide (IAN 873) e dois clones poliplóides (IAAC 207, 222) de Hevea brasiliensis Muell. Arg. Acta Amazonica. 11(1): 35-47.

Mendonça, M. S. DE. 1980. Aspectos anatómicos e distribuição de vasos laticiferos de algumas espécies de Manihot (maniçoba). Tese. CNPq/INPA. 187pp.

Metcalfe, C. R.; Chalk, L. 1950. Anatomy of the dicotyledons; leaves, stem, and wood in relation to taxonomy with notes on eco- 
nomic uses. Oxford: Clarendon Press. v.

2, $724 \mathrm{pp}$.

Patiòo, J, C. 1986. Microtecnia vegetal. México: Trillas, 106pp.

Paviani, T. I. 1974. Sobre a ocorrência de fibras gelatinosas em Plathymenia reticulata Benth. Ciência e Cultura, 26(8): 783-786. 